\title{
Method of Evaluating Workability in Cold Pilgering of Zirconium Alloy Tube*
}

\author{
Hideaki $\mathrm{Abe}^{1}$ and Munekatsu Furugen ${ }^{2}$ \\ ${ }^{1}$ Zirco Products Co., Ltd., Shimonoseki 752-0953, Japan \\ ${ }^{2}$ Furugen and Makino Laboratory Inc., Nisinomiya 662-0875, Japan
}

The workability in the cold pilgering of a zirconium alloy tube was investigated. In this study, a compression test was proposed as a method of evaluating cold workability. Compression test results showed the effects of heat treatment in the fabrication process and the texture of the tube on the cold workability of a Zircaloy-4 tube shell. Cold pilgering test results ascertained that the reduction in the height of the circumferentialdirection specimen of the tube shell at the crack initiation in the compression test was a good measure of cold workability. The numerical analysis results of cold pilgering proved the validity of the compression test as a method of evaluating cold workability. [doi:10.2320/matertrans.P-M2010812]

(Received August 17, 2009; Accepted February 23, 2010; Published May 26, 2010)

Keywords: tube rolling, workability, compression test, numerical analysis, zirconium, zircaloy, hexagonal closed-packed metal, texture, cold pilgering

\section{Introduction}

In light water reactors (LWRs), a zirconium alloy tube is used for the cladding of $\mathrm{UO}_{2}$ pellet fuels. The cladding tube must be of high quality to ensure the safety of the reactors.

Zirconium $(\mathrm{Zr})$ has two allotropic modifications. The transformation point of $\mathrm{Zr}$ is about $860^{\circ} \mathrm{C}$. The $\alpha$-form is hexagonal closed-packed (i.e., hcp structure) and is stable up to the transformation point. The $\beta$-modification, which is stable from the transformation point to the melting point, is body-centered cubic (i.e., bcc structure).

All practical $\mathrm{Zr}$ alloys used in LWRs, for example, Zircaloy-4 specified in the standard of American Society for Testing and Materials, contain $\mathrm{Zr}$ of $98 \%$ or more and show an hcp structure below the transformation point. The hcp structure shows a strong crystallographic anisotropy and subsequently has a few slip and twin systems in crystal deformation. Thus, the $\mathrm{Zr}$ alloys were previously classified as metallic materials that are difficult to deform; ${ }^{1)}$ however, recently, a practical $\mathrm{Zr}$ alloy tube has been fabricated steadily by cold pilgering.

Figure 1 shows a process flow of a $\mathrm{Zr}$ alloy tube shell. Mixed compacts of row zirconium material and additional alloy elements are melted in a vacuum arc melting furnace to fabricate a $\mathrm{Zr}$ alloy ingot. The ingot is hot-forged to obtain long solid billets. The billets are heated up to the $\beta$-phase (about $1000^{\circ} \mathrm{C}$ ) and instantly quenched by a coolant to homogenize both the chemical composition and the structure. The billets are machined into hollow billets and subsequently hot-extruded at $\alpha$-phase temperature. The extruded tubes are $\alpha$-phase-annealed, cold-pilgered and $\alpha$-annealed to tube shells. To obtain a cladding tube, each tube shell is repeatedly cold-pilgered and $\alpha$-annealed several times. Finally, the outer surface is finished by polishing, and the inner surface is finished by blasting or pickling.

Figure 2 shows an illustration of the cold pilgering process. The tools used are one pair of roll dies and a mandrel. The roll

*This Paper was Originally Published in Japanese in J. JSTP 49 (2008) 906-910

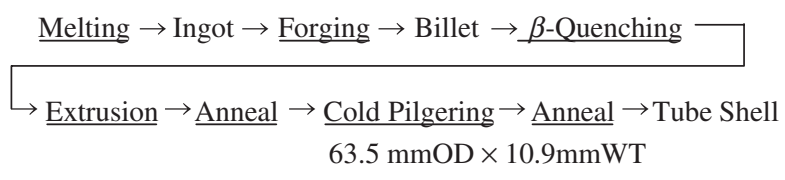

Fig. 1 Process flow of $\mathrm{Zr}$ alloy tube shell.

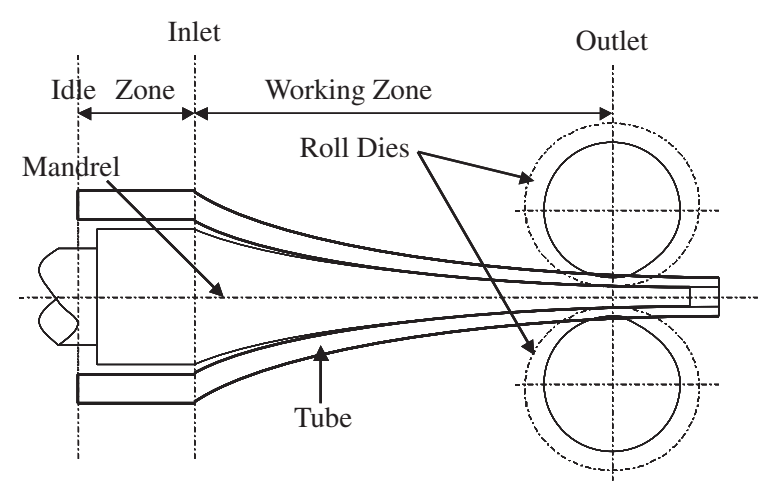

Fig. 2 Schematic illustration of cold pilgering process.

dies have decreasing caliber from the inlet to the outlet on the outer surface. In pilgering, the roll dies are rotated and simultaneously reciprocated, and the outer diameter of the tube is reduced depending on the caliber. The mandrel, which has a tapered shape in the rolling direction, is located inside the tube. Diameter and wall thickness are reduced in a number of forming steps (so-called "shots"), and the tube is elongated in the axial direction. In each shot, the mother tube is advanced and rotated during the idle zone at a fixed feed rate and a fixed turn angle, respectively, to repeat the rolling in cold pilgering continually.

A large cross-sectional reduction is possible in cold pilgering; however, a fissure on the inner surface may be formed under an operating condition because the tube is flattened during rolling. ${ }^{2)}$ The authors previously confirmed the effect of a rolling parameter, Q-factor (i.e., the ratio of wall thickness reduction to diameter reduction), ${ }^{3)}$ and the effect of roll die caliber. ${ }^{4}$ 
Some new $\mathrm{Zr}$ alloys have been developed in order to extend the life of nuclear fuel in LWRs. ${ }^{5)}$ In the development of new $\mathrm{Zr}$ alloys, the study of the fabrication process, as well as that of chemical composition, is important. In particular, it is very important for a $\mathrm{Zr}$ alloy cladding tube to prevent the formation of fissures in cold pilgering. To obtain a highquality cold-pilgered tube, an appropriate method of evaluating workability in cold pilgering has been desired. Such an appropriate evaluation method is expected to lead to a new fabrication process of improving deformability.

The authors previously studied the deformability of a $\mathrm{Zr}$ alloy tube, in which a unique high-frequency heat treatment process was applied. ${ }^{6}$ ) Their compression test confirmed that the special heat treatment affected the deformability of the $\mathrm{Zr}$ alloy tube. In the present study, the validity of the compression test as a general method of evaluating cold workability is investigated. Tube shells, the heat treatment conditions of which in the fabrication process are systematically varied, are investigated by metallurgical, compression, and cold pilgering tests. A numerical analysis of cold pilgering is conducted in order to determine the stress and strain in the tube during pilgering. From the analytical results, the relationship between cold deformability and fissure formation on the cold-pilgered tube is discussed, and the validity of the compression test as the method of evaluating workability is confirmed.

\section{Experimental}

The test material is Zircaloy-4, the chemical composition of which is shown in Table 1. The tested tube shells are fabricated by the process flow shown in Fig. 1. In the present study, the conditions of three processes, namely, billet $\beta$ quenching, extrusion preheating, and $\alpha$-annealing after cold pilgering, are varied. The process conditions of ten types of tube shell are shown in Table 2 . The cooling rate of billet $\beta$ quenching in the transformation zone is varied under three conditions using different cooling methods, achieving rapid, medium, and slow cooling. The rapid cooling is achieved by hollow-billet quenching. The two other types of cooling involve quenching on a solid billet with different coolants. The extrusion preheating temperature is varied under two conditions, and the annealing temperature after extrusion is chosen to be $649^{\circ} \mathrm{C}$. The $\alpha$-annealing temperature after cold pilgering is varied under five conditions, from $649^{\circ} \mathrm{C}$ to $788^{\circ} \mathrm{C}$. The tube shells, which are $63.5 \mathrm{~mm}$ in outer diameter and $10.9 \mathrm{~mm}$ in wall thickness, are surface-conditioned by polishing and pickling, and subjected to metallurgical, compression, and cold pilgering tests.

In the metallurgical test of the tube shells, the X-ray measurement of the crystallographic texture, microstructural observation and hardness measurement are conducted. Specimens, which are obtained from the midwall of a tube, are measured by X-ray diffraction to determine the texture. The measured plane is the (0002) basal plane of the hcp structure. The measurement results are summarized in a pole figure and the quantitative texture index $f_{\mathrm{i}}$ values are obtained by the Kearns method. ${ }^{7)}$ The microstructure of each process sample from billet forging to annealing after cold pilgering is observed by polarized optical microscopy. Also, hardness is
Table 1 Chemical composition/mass $\%$.

\begin{tabular}{cccccc}
\hline $\mathrm{Sn}$ & $\mathrm{Fe}$ & $\mathrm{Cr}$ & $\mathrm{O}$ & $\mathrm{C}$ & $\mathrm{Zr}$ \\
\hline 1.30 & 0.21 & 0.11 & 0.10 & 0.01 & Balance \\
\hline
\end{tabular}

Table 2 Experimental process conditions of tube shell.

\begin{tabular}{|c|c|c|c|}
\hline \multirow[b]{2}{*}{ No. } & \multicolumn{3}{|c|}{ Process condition } \\
\hline & $\begin{array}{c}\text { Billet } \\
\beta \text {-Quenching } \\
\text { Cooling Rate }\end{array}$ & $\begin{array}{c}\text { Preheat } \\
\text { Temperature of } \\
\text { Extrusion }\end{array}$ & $\begin{array}{c}\text { Anneal } \\
\text { Temperature after } \\
\text { pilgering }\end{array}$ \\
\hline 1 & \multirow{2}{*}{ Rapid: $100^{\circ} \mathrm{Cs}^{-1}$} & $649^{\circ} \mathrm{C}$ & $649^{\circ} \mathrm{C}, 2 \mathrm{~h}$ \\
\hline 2 & & $750^{\circ} \mathrm{C}$ & $649^{\circ} \mathrm{C}, 2 \mathrm{~h}$ \\
\hline 3 & \multirow{6}{*}{ Medium: $30^{\circ} \mathrm{C} \mathrm{s}^{-1}$} & $649^{\circ} \mathrm{C}$ & $649^{\circ} \mathrm{C}, 2 \mathrm{~h}$ \\
\hline 4 & & $649^{\circ} \mathrm{C}$ & $700^{\circ} \mathrm{C}, 2 \mathrm{~h}$ \\
\hline 5 & & $649^{\circ} \mathrm{C}$ & $732^{\circ} \mathrm{C}, 2 \mathrm{~h}$ \\
\hline 6 & & $649^{\circ} \mathrm{C}$ & $750^{\circ} \mathrm{C}, 2 \mathrm{~h}$ \\
\hline 7 & & $649^{\circ} \mathrm{C}$ & $788^{\circ} \mathrm{C}, 2 \mathrm{~h}$ \\
\hline 8 & & $750^{\circ} \mathrm{C}$ & $732^{\circ} \mathrm{C}, 2 \mathrm{~h}$ \\
\hline 9 & \multirow{2}{*}{ Slow: $15^{\circ} \mathrm{Cs}^{-1}$} & $649^{\circ} \mathrm{C}$ & $649^{\circ} \mathrm{C}, 2 \mathrm{~h}$ \\
\hline 10 & & $750^{\circ} \mathrm{C}$ & $732^{\circ} \mathrm{C}, 2 \mathrm{~h}$ \\
\hline
\end{tabular}

\begin{tabular}{|c|c|}
\hline Sampling & \multicolumn{1}{c|}{ Test method } \\
\hline Test machine: Instron type \\
Specimen: $4 \mathrm{mmD} \times 8 \mathrm{mmH}$ \\
or $8 \mathrm{mmD} \times 8 \mathrm{mmH}$ \\
Compression speed:5mm/min \\
Compress
\end{tabular}

Fig. 3 Compression test.

measured in each process sample by the Rockwell hardness test.

In the present study, the compression test is proposed as a method of evaluating workability in the cold pilgering of a $\mathrm{Zr}$ alloy tube. The sampling of specimens and the compression test method are shown in Fig. 3. Specimens are obtained from three directions, that is, the radial, circumferential, and axial directions of the tube shell. The specimens are solid cylindrical, $4 \mathrm{~mm}$ or $8 \mathrm{~mm}$ in diameter and $8 \mathrm{~mm}$ in height; their surfaces are finished smoothly. The compression test is performed in an Instron test machine at room temperature. Both the top and bottom sides of the specimens are lubricated by oil and the compression speed is kept constant at 5 $\mathrm{mm} / \mathrm{min}$. During compression, the actual displacement and load are recorded continuously; thus, the crack initiation on the specimens is certainly observed. The ultimate reduction in height, $R_{\mathrm{c}}(\%)$, at the crack initiation is calculated as

$$
R_{\mathrm{c}}(\%)=\frac{H-h}{H} \times 100,
$$


where $H$ is the height of the specimen before the test and $h$ is the height of the specimen after the test. Also, the $0.2 \%$ yield strength and the ultimate compressive strength are obtained by recording the displacement and load.

The cold pilgering test of the tube shell is conducted using the reducing schedule below, and the reduction in area is $51 \%$.

[Schedule (OD: outer diameter, WT: wall thickness), unit: $\mathrm{mm}]$

$$
O D 63.5 \times W T 10.9 \rightarrow O D 44.4 \times W T 7.6
$$

The cold pilgering test is performed using a typical 75VMRtype mill manufactured by Meer, the roll die diameter of which is $370 \mathrm{~mm}$, and the working-zone length is $750 \mathrm{~mm}$. The flaw detection of the cold-pilgered tube is performed by ultrasonic testing, penetration testing, and visual inspection.

\section{Results}

The metallurgical investigation of tube shells includes the analyses of crystallographic texture, microstructure, and hardness.

The (0002) plane pole figure of a tube shell is shown in Fig. 4, together with a schematic of the texture. The measured tube shell was No. 5 in Table 2, and its cooling rate of billet quenching was medium, its extrusion preheating temperature was $649^{\circ} \mathrm{C}$, and its annealing temperature after cold pilgering was $732^{\circ} \mathrm{C}$. As the texture index, the Kearns factor $f_{\mathrm{i}}(\mathrm{i}=\mathrm{r}, \theta, 1)$ was calculated. The $f_{\mathrm{i}}$ value indicates the $c$-axis orientation ratio in the tube. The calculation results were $f_{\mathrm{r}}=0.35, f_{\theta}=0.58$, and $f_{1}=0.07$, where $\mathrm{r}, \theta$, and 1 refer to the radial, circumferential, and axial directions of the tube, respectively. The results showed that the circumferential $c$-axis orientation ratio was the highest, and the crystallographic anisotropy of the tube shell proved to be very strong. Other tube shell measurement results showed that the textures of tube shells were similar regardless of the process condition.

The microstructures in the two cases of rapid and slow $\beta$ quenching on the billets are shown in Fig. 5. The observed portion of the microstructures was near the outer surface, in which the effect of $\beta$-quenching was supposed to be significant. After $\beta$-quenching, an acicular structure was observed, and in as-extruded tubes and annealed extrusions, partially mixed and courser grains were observed. Finally, in all cases, normal grains were observed after the annealing of

\begin{tabular}{|c|c|}
\hline (0002)plane pole figure & Schematic of Texture \\
\hline Axial & c-axis \\
\hline
\end{tabular}

Fig. 4 Pole figure and texture of tube shell (Tube shell No. 5).

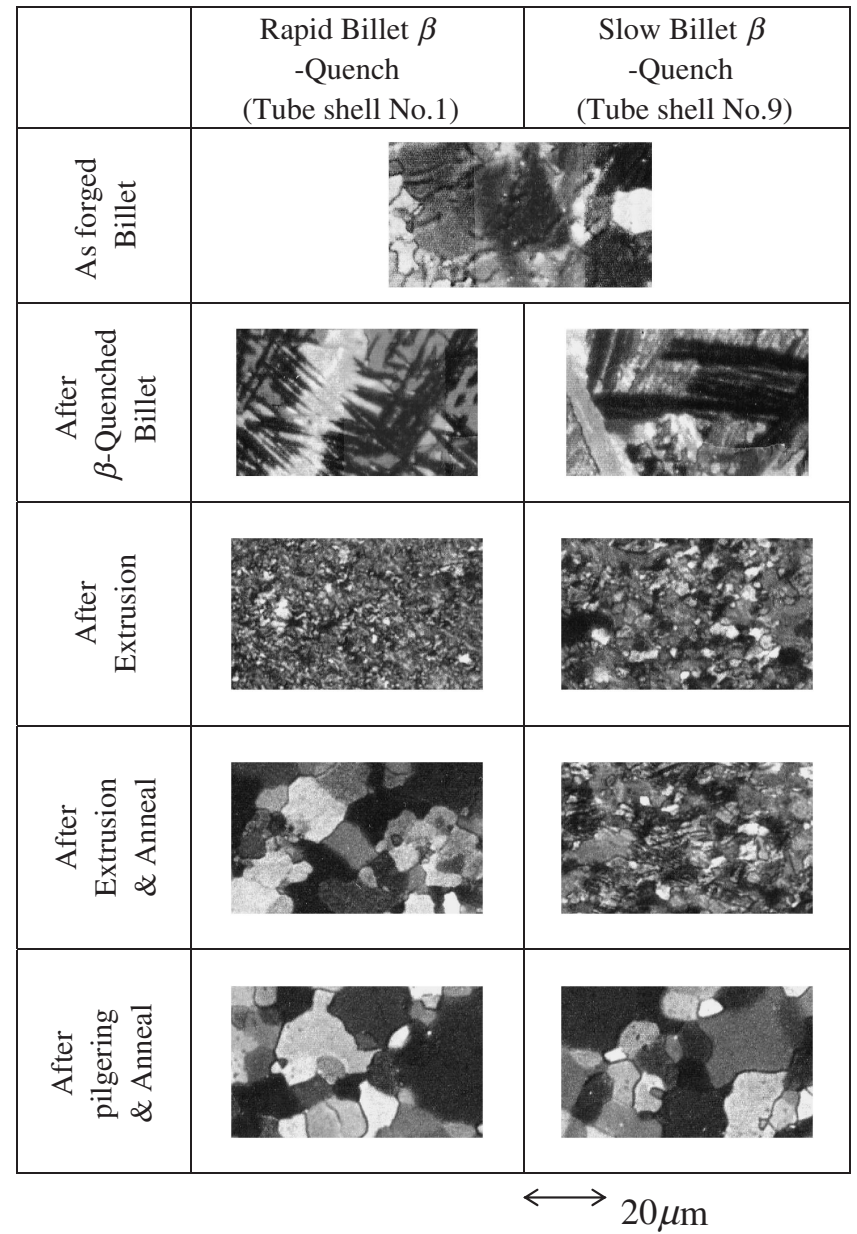

Fig. 5 Change of microstructure in the process (Outer side of billet and tube, Transverse).

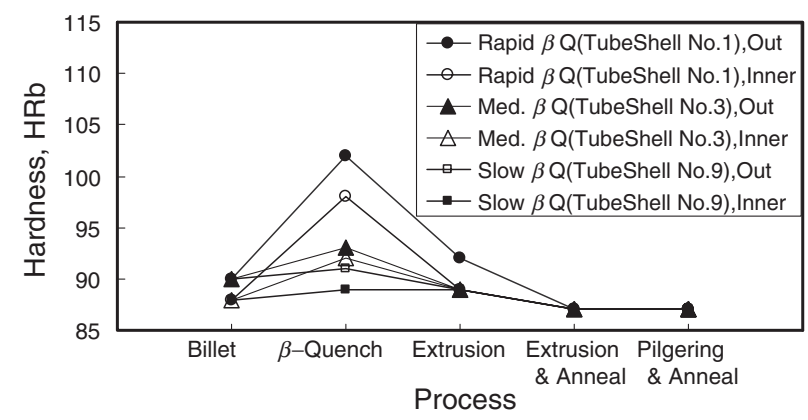

Fig. 6 Change of hardness in the process.

cold-pilgered tubes, i.e., tube shells. Also, the microstructure of the medium $\beta$-quenching case was similar to that of the slow quenching case in each process.

Cross-sectional hardness was measured near both the outer and inner surfaces. The hardness measurement results are shown in Fig. 6. The rapid $\beta$-quenching caused a significant hardening; on the other hand, the effects of the medium and slow quenching on hardening were smaller. Finally, no differences in hardness were observed in all tube shells regardless of the process condition.

No differences in both microstructure and hardness in all types of tube shell were also observed. The three-direction compression test results of the tube shells were compared. 


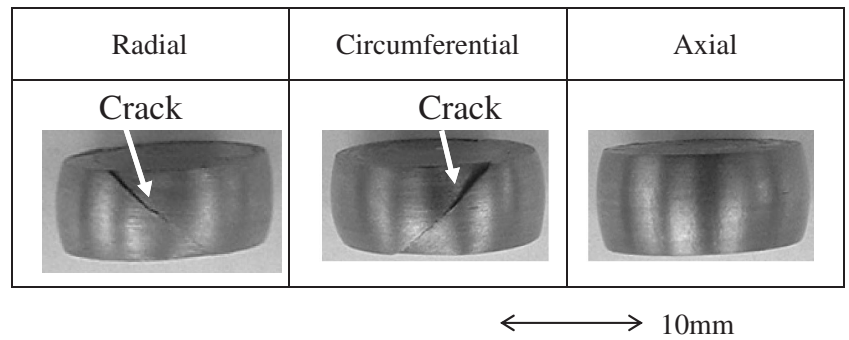

Fig. 7 Specimens after compression test $(8 \mathrm{mmD} \times 8 \mathrm{mmH})$.

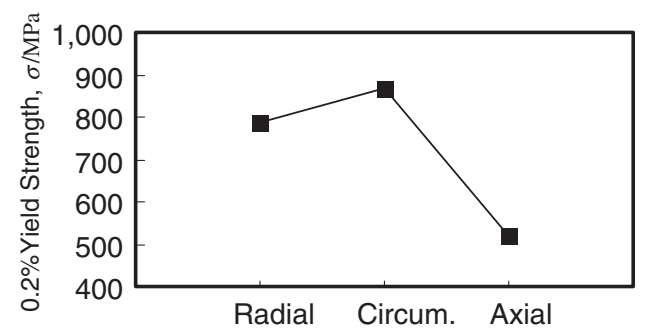

(a) $0.2 \%$ Yield Strength

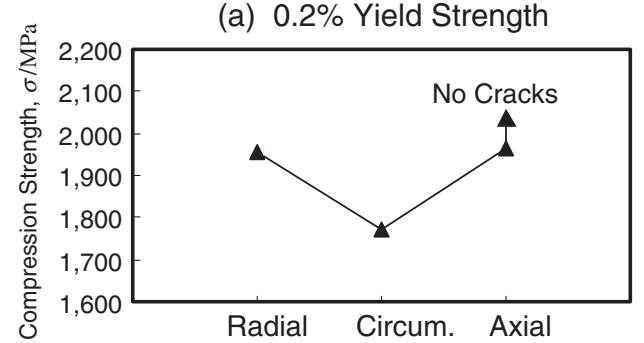

(b) Ultimate Compression Strength

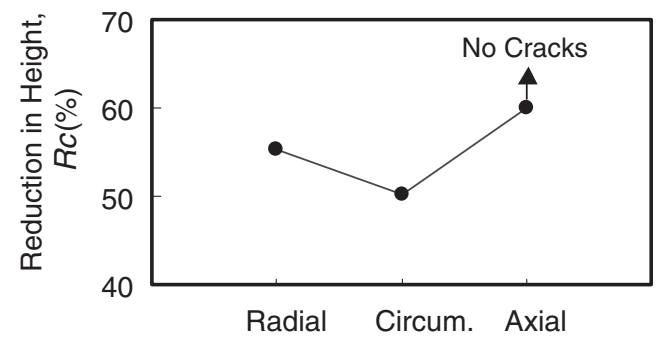

(c) Reduction in Height

Fig. 8 Compression of test results in 3 directions of tube shell (Specimen: $8 \mathrm{mmD} \times 8 \mathrm{mmH})$.

The test specimens were obtained from tube shell No. 5, the texture of which is shown in Fig. 4. The photographs of the specimens after the compression test are shown in Fig. 7, which shows slanting cracks in the circumferential- and radial-direction specimens. In contrast, no cracks were observed in the axial-direction specimen.

A comparison of three-direction compressive properties is shown in Fig. 8. At $0.2 \%$ yield strength, the circumferentialdirection value was the highest, the radial-direction value was the second highest, and the axial-direction value was much lower than those of the other two directions. However, the tendencies of the ultimate compressive strength and height reduction $R_{\mathrm{c}}$ were opposite to those of yield strength. Namely, the circumferential direction had the lowest value, the radial direction had the second lowest value, and the axial direction had no cracks until a height reduction of more than $70 \%$.

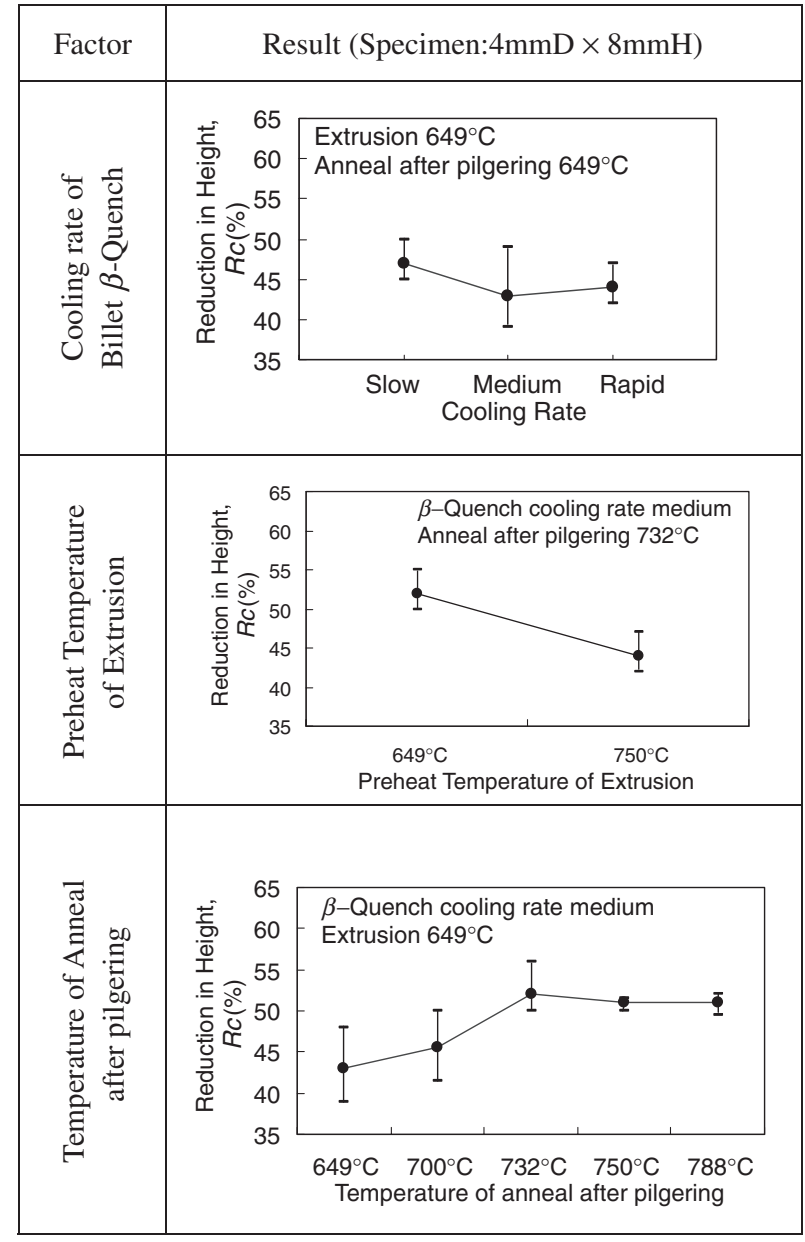

Fig. 9 Relationship between the process condition and $R_{\mathrm{c}}$ in the circumferential direction of tube shell.

It is known that zirconium inherently shows crystallographic and mechanical anisotropies, and has a lower deformability in the c-axial direction of an hcp structure. ${ }^{8)}$ From the results shown in Fig. 4, the order of $c$-axis orientation ratio was in the circumferential, radial and axial directions. The $c$-axis orientation ratio order corresponded to the order of the ultimate compressive strength and the reduction in height. The anisotropy of compressive properties was proved to be caused by $c$-axis orientation, i.e., the texture.

Then, compression tests of all other tube shells were performed. The test results showed that the ultimate reduction in the height of the circumferential-direction specimen was lower than those of the specimens in the other two directions. Therefore, the results mentioned below are restricted to the results of the circumferential direction. The relationship between the process condition and the ultimate reduction in the height of the circumferential-direction specimen is shown in Fig. 9. As for the cooling rate of billet $\beta$-quenching, the ultimate reduction in height increased as the cooling rate decreased. As for the extrusion preheating temperature, the low temperature $\left(649^{\circ} \mathrm{C}\right)$ showed higher values than the high temperature $\left(750^{\circ} \mathrm{C}\right)$. As for the annealing temperature after pilgering, the high temperature showed higher values than the low temperature, and above $732^{\circ} \mathrm{C}$, stable higher values were obtained. 
Table 3 Cold pilgering test results.

\begin{tabular}{|c|c|c|c|c|c|}
\hline \multirow[b]{2}{*}{ No. } & \multicolumn{3}{|c|}{ Process condition } & \multirow[b]{2}{*}{$\begin{array}{l}R_{\mathrm{c}} \\
(\%)\end{array}$} & \multirow[b]{2}{*}{$\begin{array}{l}\text { Cold } \\
\text { pilgering test } \\
\text { result }\end{array}$} \\
\hline & $\begin{array}{c}\text { Billet } \\
\beta \text {-Quench }\end{array}$ & $\begin{array}{l}\text { Preheat of } \\
\text { Extrusion }\end{array}$ & $\begin{array}{c}\text { Anneal } \\
\text { after } \\
\text { pilgering }\end{array}$ & & \\
\hline 1 & \multirow{2}{*}{ Rapid } & $649^{\circ} \mathrm{C}$ & $649^{\circ} \mathrm{C}$ & 44.0 & good \\
\hline 2 & & $750^{\circ} \mathrm{C}$ & $649^{\circ} \mathrm{C}$ & 35.0 & fissures \\
\hline 3 & \multirow{6}{*}{ Medium } & $649^{\circ} \mathrm{C}$ & $649^{\circ} \mathrm{C}$ & 43.0 & good \\
\hline 4 & & $649^{\circ} \mathrm{C}$ & $700^{\circ} \mathrm{C}$ & 45.5 & good \\
\hline 5 & & $649^{\circ} \mathrm{C}$ & $732^{\circ} \mathrm{C}$ & 52.0 & good \\
\hline 6 & & $649^{\circ} \mathrm{C}$ & $750^{\circ} \mathrm{C}$ & 51.0 & good \\
\hline 7 & & $649^{\circ} \mathrm{C}$ & $788^{\circ} \mathrm{C}$ & 51.0 & good \\
\hline 8 & & $750^{\circ} \mathrm{C}$ & $732^{\circ} \mathrm{C}$ & 44.0 & good \\
\hline 9 & \multirow{2}{*}{ Slow } & $649^{\circ} \mathrm{C}$ & $649^{\circ} \mathrm{C}$ & 47.0 & good \\
\hline 10 & & $750^{\circ} \mathrm{C}$ & $732^{\circ} \mathrm{C}$ & 44.0 & good \\
\hline
\end{tabular}

The effect of each process condition on the compressive property was observed. From the point of deformability, the desirable process conditions were slower cooling in billet $\beta$-quenching, lower-temperature preheating of extrusions, and higher-temperature $\alpha$-annealing after cold pilgering.

The cold pilgering tests of all tube shells of $2 \mathrm{~m}$ length were performed at a feed rate of $5 \mathrm{~mm}$ and a turn angle of 57 degrees. The pilgering test results are shown in Table 3, together with the process condition and the circumferential ultimate reduction in height, $R_{\mathrm{c}}$. Most tube shells had good surfaces both outside and inside after the pilgering test. Only tube shell No. 2 had small longitudinal fissures on the inner surface after the pilgering test. The depth of fissures was about $0.02 \mathrm{~mm}$. Tube shell No. 2 was fabricated by rapid billet quenching, higher-temperature preheating of extrusions, and lower annealing after pilgering. The tube shell had the extremely lowest ultimate reduction in height among the tested tube shells. The pilgering test results show that the circumferential ultimate reduction in height is strongly related to the fissure formation in cold pilgering.

\section{Discussion}

Previously, Kudo et al. studied the relationship between stress and crack initiation during the compression test of annealed steel samples. ${ }^{9)}$ According to their results, the slanting cracks observed in the present study are caused by the vertical compressive stress $\sigma_{\mathrm{z}}$ and tensile stress $\sigma_{\theta}$ at the center of the side of a specimen, as shown in Fig. 10. The circumferential ultimate reduction in the height of a $\mathrm{Zr}$ alloy tube shell in the present study (from 35 to 52\%) is much lower than the values of the annealed steel samples used by Kudo et al. (from 75 to $80 \%$ ). The compression test results proved that the $\mathrm{Zr}$ alloy tube shell had a lower deformability in the circumferential direction than the annealed steel samples.

A numerical analysis of cold pilgering ${ }^{10)}$ is performed to consider the experimental results. The analysis method and results of stress and strain in the tube are shown in Fig. 11. In cold pilgering, the tube is rolled asymmetrically because it is rotated at about 60 degrees in each continual forming step.

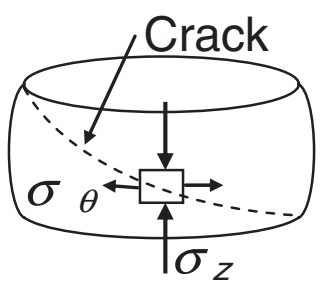

Fig. 10 Crack in compression test.

(a) Division of a tube-section in analysis

Division of tube-section :

Web part 1 and 4

Flange part 2 and 3

Stress : $\sigma_{r}, \sigma_{\theta}, \sigma_{l}$

Strain : $\varepsilon_{r}, \varepsilon_{\theta}, \varepsilon_{l}$

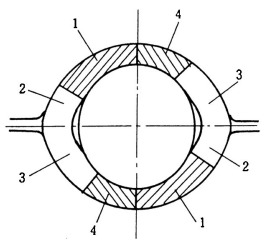

(b) Variation of stress during cold pilgering

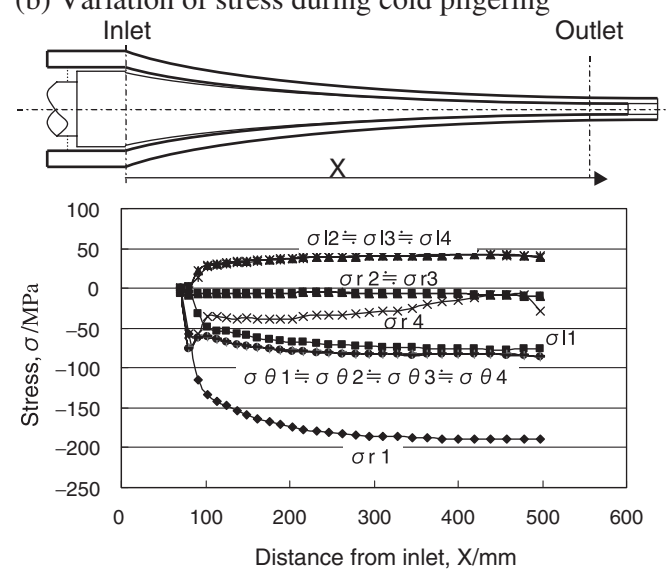

(c) Variation of strain during cold pilgering

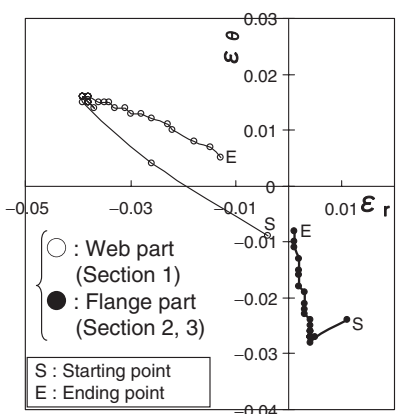

Fig. 11 Numerical analysis results of the cold pilgering.

Then, in the analysis, the tube cross section is divided into four sections, including two web parts and two flange parts, as illustrated in Fig. 11(a). On each section, the average stress $\sigma$ and strain $\varepsilon$ are calculated in the radial (r), circumferential $(\theta)$, and longitudinal (l) directions. The analysis results of stress and strain are shown in Figs. 11(b) and (c), respectively. In each web part, the inner surface of the tube is completely in contact with the mandrel, while in each flange part, the inner surface is partially in contact with the mandrel. Therefore, the analysis results of stress and strain in pilgering are markedly different between the web and flange parts. In the web part (section 1), all threedirection stresses are compressive; the large radial strain is 
contractile and the circumferential strain is tensile. While in the flange part (sections 2 and 3), radial and axial stresses are compressive and tensile, respectively; the large circumferential strain is contractile and the small radial strain is tensile.

The fissure formation mechanism on the inner surface of the cold-pilgered tube is discussed using the results of both the compression test and the analysis of cold pilgering. As mentioned above, all three-direction stresses in the web part are compressive and the radial deformation is contractile, and the circumferential deformation is tensile. Thus, in the web part, fissures hardly form. On the other hand, the flange part is subjected to a larger compressive stress and the circumferential deformation is contractile. In addition, the inner surface is free, that is, it is partially in contact with the mandrel. Consequently, in the flange part, fissures likely form on the inner surface. In particular, the $\mathrm{Zr}$ alloy tube shell has a lower circumferential compressive deformability than the annealed steel samples; thus, fissures likely form on the inner surface in cold pilgering. From the viewpoint of evaluation methodology for the cold pilgering of the $\mathrm{Zr}$ alloy tube, the circumferential ultimate reduction in height proved to be an appropriate method of evaluating workability.

\section{Conclusion}

The validity of the compression test as a method of evaluating the workability of a $\mathrm{Zr}$ alloy tube in cold pilgering was investigated. Compression test results showed that both the crystallographic texture and the heat treatment in the fabrication process affected the cold workability of a $\mathrm{Zr}$ alloy tube shell. Actual cold pilgering tests proved that the formation of fissures on a cold-pilgered tube was related to the ultimate reduction in the height of the tube shell in the compression test. The analysis results of the cold pilgering ensured the relationship between the compressive deformability and the formation of fissures in cold pilgering. Accordingly, the ultimate reduction in the height of the circumferential-direction specimen of the tube shell in the compression test proved to be a good measure of cold workability. Therefore, the method is effective for evaluating the workability of a newly developed $\mathrm{Zr}$ alloy tube that is not yet subjected to cold pilgering.

\section{REFERENCES}

1) T. Konishi: J. JSTP 19 (1978) 302-307.

2) Z. Bembenek, H. Wiesner and J. Starek: Proc. 3rd. Jpn.-Czech. Jt. Symp. (1981) pp. 135-153.

3) H. Abe, H. Tarui, T. Kobayashi, M. Honji and T. Konishi: ASTM STP 1132 (1991) 35-47.

4) H. Abe, K. Takeda, A. Uehira, H. Anada and M. Furugen: ASTM STP 1354 (2000) 425-459.

5) H. Abe et al.: Proc. 2006 Annual Meeting of the AESJ (2006) pp. 205213.

6) H. Abe, K. Matsuda, T. Hama, T. Konishi and M. Furugen: ASTM STP 1245 (1994) 285-306.

7) J. J. Kearns: Report WAPD-TM-472 WH (1965) pp. 2-4.

8) E. Tenckhoff: ASTM STP 966 (1988) 55-56.

9) H. Kudo and K. Aoi: J. JSTP 8 (1967) 17-27.

10) M. Furugen and C. Hayashi: J. Mech. Work. Tech. 10 (1984) 273-286. 